\title{
O RECONHECIMENTO DA IDENTIDADE CULTURAL INDÍGENA E A PROTEÇÃO DOS DIREITOS DA PERSONALIDADE
}

\author{
THE RECOGNITION OF INDIGENOUS CULTURAL IDENTITY AND THE \\ PROTECTION OF PERSONALITY RIGHTS
}

\author{
Alessandro Severino Valler Zenni ${ }^{\mathrm{I}}$ \\ Beatriz Caroline Fiaes ${ }^{\text {II }}$
}

I Universidade Estadual de Maringá, PR,
Brasil. Doutor em Filosofia do Direito.
E-mail: biaacarol@hotmail.com
II Centro Universitário de Maringá
- UniCesumar, Maringá, PR, Brasil.
Mestranda em Direito.
E-mail: beatrizcarolinefiaes@gmail.com

DOI: http://dx.doi.org/10.20912/rdc.v16i40.358

Recebido em: 30/03/2021

Aceito em: 18/11/2021

\begin{abstract}
Resumo: O presente artigo aborda a relação entre os direitos da personalidade e a identidade pessoal, aspecto fundamental para a formação e caracterizaçấo da individualidade do ser humano, uma vez que determina sua definição ontológica e seu relacionamento com os demais, e, portanto, merece ser tutelado como uma das prerrogativas da personalidade, embora não expresso no rol constitucional e civil. A pesquisa é desenvolvida no sentido de demonstrar que a identidade e a cultura, principalmente no que se refere aos povos indígenas, é determinante para a manifestação da dignidade da pessoa humana, considerada doutrinariamente como cláusula geral dos direitos da personalidade. Diante disso, abordase o direito a ser diferente como uma extensão dos direitos fundamentais de igualdade e liberdade. Isto posto, mediante o emprego do método dedutivo e por intermédio do procedimento bibliográfico, é razoável inferir que é essencial ao poder público e aos particulares o reconhecimento e o respeito pela identificação, autonomia, e elementos culturais das comunidades indígenas.
\end{abstract}

Palavras-chave: Direitos da personalidade; Dignidade humana; Identidade; Cultura; Indígenas.

Abstract: The present article approaches the relationship between personality rights and personal identity, a fundamental aspect for the formation and characterization of the individuality of human beings, since it determines their ontological definition and their relationship with others, and therefore deserves to be protected as one of the prerogatives of personality, although not expressed in the constitutional and civil list. The research is developed in order to demonstrate that identity and culture, especially as far as indigenous peoples are concerned, is determinant for 
the manifestation of human dignity, considered doctrinally as a general clause of the rights of personality. Therefore, the right to be different is approached as an extension of the fundamental rights of equality and freedom. That said, through the use of the deductive method and by means of the bibliographical procedure, it is reasonable to infer that it is essential for public authorities and private individuals to recognize and respect the identification, autonomy, and cultural elements of indigenous communities.

Keywords: Personality rights; Human dignity; Identity; Culture; Indigenous people.

\section{Introdução}

É impossível especificar com exatidão o período inicial em que os indígenas se estabeleceram no território brasileiro. Entretanto, é corrente que à época em que os primeiros colonizadores ingressaram, existiam incontáveis comunidades e povos indígenas difundidos pelo país, todos com suas próprias características, costumes, tradiçôes e crenças, tendo como denominador em comum a essencialidade da terra e da natureza como elementos fundamentais para sua sobrevivência e conservação.

A história revela, todavia, que as nações colonizadoras, uma vez que superioras em armamentos, abordaram os povos nativos de forma ofensiva, destrutiva e violenta, o que contribuiu para a aniquilação de indígenas, com consequências que são reproduzidas até a atualidade. $\mathrm{Na}$ sociedade pós-moderna, cada vez mais as reflexôes a respeito da preservação da natureza e da convivência em harmonia tem alcançado mais relevância e aceitação. Caso a aproximação com os indígenas houvesse sido diversa, desde o princípio, é possível que o cenário brasileiro fosse muito mais enriquecido com conhecimento e equilíbrio.

Esse entendimento deriva-se do fato de que as culturas dos diversos povos indígenas são heterogêneas e proveitosas para os diversos âmbitos da vida. $\mathrm{O}$ domínio e emprego dos elementos naturais para a solução de vários problemas do homem, por exemplo, que a princípio foi considerado como práticas obsoletas e primitivas, é amplamente investigado atualmente, e reconhecido como significativo e relevante. Desta forma, práticas culturais exercidas pelos indígenas e que os identificavam e determinavam seu pertencimento possuem a mesma validade e importância que as condutas exercidas por povos que se intitulam "superiores".

Em diferentes épocas o ser humano procurou estabelecer um padrão aceitável de biotipos, comportamentos, pensamentos e crenças, uniformizando os indivíduos a um único arquétipo, suprimindo e inferiorizando indivíduos que divergissem e destoassem desse modelo. Por essa razão os direitos fundamentais como igualdade, liberdade e fraternidade se demostram profundamente necessários e foram de sobremodo difundidos entre os Estados, a fim de promover uma vida digna a todos os indivíduos sem distinção.

A presente pesquisa intenciona manifestar a hipótese de as culturas, práticas, crenças, e demais que identificam os povos indígenas são componentes do direito da identidade, que particulariza e represente o indivíduo perante si e na relação com os demais membros particulariza e represente o indivíduo perante si e na relação com os demais membros com quem convive, de 
forma que tal direito deve ser reconhecido como um direito da personalidade, ainda que não expressamente no ordenamento jurídico.

Essa concepção se fundamenta no princípio fundamental da dignidade da pessoa humana, cláusula geral de tutela da personalidade do homem, originada mesmo antes do seu nascimento, que possibilita e garante o desenvolvimento do indivíduo com plenitude, de forma que o reconhecimento cultural do indígena, sem qualquer preconceito e intolerância, é uma expressão dessa dignidade.

\section{Consideraçóes a respeito dos direitos da personalidade}

A exteriorização dos direitos da personalidade como categoria independente, iniciou-se no século XX com a promulgação da Constituição de Weimar em 1919, estabelecendo institutos próprios do direito privado, que foram evidenciados posteriormente a partir do fim da segunda guerra mundial, e uma vez que constatadas as crueldades comedidas em prol dos propósitos do Estado, bem como as consequentes hostilidades nas relações intersubjetivas, foi impositiva a exigência pela defesa pessoal ${ }^{1}$.

A princípio, conforme o ensinamento de Schreiber, os direitos da personalidade eram compreendidos como fundamentais ao homem, a ainda que a essência da pessoa dependeria destes direitos para existir como indivíduo, considerando atributos que ainda vigoram no ordenamento jurídico, como a impossibilidade de serem alienados, revogados, renunciados e concedidos, que deveriam ser tutelados e defendidos ante os interesses dos particulares e do Estado².

A tarefa de conceituar os direitos da personalidade é complexa e profunda, considerando que perpassa pela análise de vários aspectos, vez que essa definição não se encontra positivada no ordenamento jurídico, bem como que a doutrina náo é unânime na delimitação desses direitos, existindo, dentre outras, duas principais teorias defendidas pelos doutrinadores, ou seja, a positivista e a naturalista.

Os direitos da personalidade para alguns jusnaturalistas decorrem de um direito natural estabelecido por Deus, devendo ser reconhecidos, para outros são direitos naturais uma vez que procedem de uma lei da natureza, e ainda se originam da razão intrínseca e característica do ser humano ${ }^{3}$. A doutrina positivista, por outro lado, compreende os direitos da personalidade como subjetivos, que compóem o mínimo necessário e fundamental para o conteúdo da personalidade, ressaltando que esses direitos são apenas os que estão positivados pelo legislador no ordenamento jurídico ${ }^{4}$.

É decorrente da teoria jusnaturalista a compreensão de que a declaração de direitos, e os direitos da personalidade são direitos naturais, originários, protegidos e invioláveis em oposição a qualquer interferência pública ou privada . Nessa lógica, conforme a instrução de Adriano de

1 CANTALLI, Fernanda Borghetti. Direitos da personalidade: disponibilidade relativa, autonomia privada e dignidade humana. Porto Alegre: Livraria do advogado, 2009, p. 50-52.

2 SCHREIBER, Anderson. Direitos da personalidade. 2. ed. São Paulo: Atlas, 2013, p. 5.

3 BORGES, Roxana Cardoso Brasileiro. Direitos da personalidade e autonomia privada. 2. ed. São Paulo: Saraiva, 2007, p. 22-23.

4 BITTAR, Carlos Alberto. Os direitos da personalidade. 8. ed. São Paulo: Saraiva, 2015, p. 37-38.

5 ZANINI, Leonardo Estevam. Direitos da Personalidade: aspectos essenciais. São Paulo: Saraiva, 2011, p. 121. 
Cupis ${ }^{6}$, seria possível considerar como direitos da personalidade todos aqueles que promovem conteúdo à personalidade, uma vez que diante da inexistência de certos direitos, qualificados como essenciais a própria pessoa deixaria de existir.

O legislador brasileiro estipulou os direitos da personalidade no artigo $5^{\circ}, \mathrm{X}$ da Constituição Federal de 1998, e no Código Civil Brasileiro, a partir do artigo 11, sendo incorporado o direito à vida, à intimidade, à vida privada, à honra e à imagem, sendo também protegidas as demais prerrogativas derivadas desses direitos.

É relevante a consideração a respeito das circunstâncias necessárias para que o homem disponha de personalidade e dos direitos dela provenientes. Para a maioria da doutrina, a partir do momento em que o ser humano é considerado pessoa, origina-se também a personalidade, e por meio desta é facultado ao sujeito obter bens e protegê-los, que sáo os chamados direitos da personalidade, sendo inclusive o nascituro e o concepturo possuidor de algumas dessas prerrogativas ${ }^{7}$.

A percepçáo dos direitos da personalidade pode ser realizada a partir de duas perspectivas, quais sejam, sob os aspectos originários, próprios dos indivíduos, que existem desde o nascimento do ser humano, e ainda sob o enfoque das relaçóes do homem com a sociedade, manifestando e exteriorizando suas características como ser moral e social ${ }^{8}$. Assim, infere-se que a personalidade do ser humano é concebida a partir de seu conhecimento e consciência sobre si mesmo, e pelas impressóes dos demais membros com quem convive.

Nesse sentido, o objeto dos direitos da personalidade são os bens e valores intrínsecos e fundamentais de cada indivíduo, compreendidos em sua dimensão física, que envolve o direito à vida e a disposição do próprio corpo, na esfera moral, abarcando o direito à liberdade, à imagem, à honra, à identidade, ao segredo, e ainda no plano intelectual, incluindo o direito à liberdade de pensamento e direito de autor, garantindo assim a prerrogativa de que sejam defendidos e exigido seu cumprimento em relação aos terceiros? .

Importante destacar que sob certas perspectivas, os direitos protegidos em âmbitos e planos diversos são distintamente denominados, de modo que em relação à esfera Internacional, intitulam-se Direitos Humanos, ao se tratar da perspectiva constitucional, tem-se os chamados Direitos Fundamentais, e no que concerne às relaçôes disciplinadas pelo Direito Civil, essas prerrogativas são designadas como Direitos da Personalidade ${ }^{10}$. Do mesmo modo Fernanda Borghetti Cantalli afirma que "Não há diferença substancial entre os direitos da personalidade e os direitos fundamentais. Simplesmente os direitos da personalidade são direitos fundamentais em sede de direito Privado [...]" ${ }^{\prime 1}$.

As relações humanas, reflexôes, e comportamentos estão constantemente em evolução, e com efeito, todos os organismos e institutos são variáveis e voláteis. O direito, portanto, como instrumento de proteção do homem não deve ser restrito e inerte a essas transformaçôes, apesar

6 CUPIS, Adriano de. Os direitos da personalidade. Sáo Paulo: Quorum, 2008, p. 23.

7 SZANIAWSKI, Elimar. Direitos da personalidade e sua tutela. 2. ed. São Paulo: Revista dos Tribunais, 2005, p. 74,80 .

8 BITTAR, Carlos Alberto. Os direitos da personalidade. 8. ed. São Paulo: Saraiva, 2015, p. 41.

9 AMARAL, Francisco. Direito civil: introdução. 5.ed. Rio de Janeiro: Renovar, 2003, p. 249-250.

10 BITTAR, Carlos Alberto. Os direitos da personalidade. 8. ed. São Paulo: Saraiva, 2015, p. 31-32.

11 CANTALLI, Fernanda Borghetti. Direitos da personalidade: disponibilidade relativa, autonomia privada e dignidade humana. Porto Alegre: Livraria do advogado, 2009, p. 129. 
da evidente morosidade com que as novas relaçôes são incorporadas pelo legislativo, em relação com a transitoriedade das instituiçôes no mundo pós-moderno.

É esse o posicionamento de Roxana Borges ao estabelecer que inexiste taxatividade ao se tratar dos direitos da personalidade, considerando que a relação desses direitos está constantemente se ampliando, principalmente em consequência de novas tecnologias, relaçóes econômicas, bem como necessidade de proteção contra possíveis lesôes não apenas do Estado contra a vida, liberdade e integridade, mas de particulares, sendo possível se anunciar um direito geral da personalidade ${ }^{12}$.

Relativamente aos fundamentos do direito geral de personalidade, Hubmann declara que a dignidade humana, a individualidade e a pessoalidade são elementos que integram a personalidade e estruturam o indivíduo, de sorte que a dignidade é o elemento que concede o significado o homem no Universo, a individualidade o componente que torna o ser humano único, dotado de características próprias desde o nascimento, desenvolvido ao longo da vida e a pessoalidade a conexão do sujeito com toda a sociedade e seus princípios éticos, tutelando suas particularidades (Hubmann, 1967, p. 60, apud Szaniawski, 2005, p. 114) ${ }^{13}$.

É razoável a tutela das situaçóes e relaçóes jurídicas, inclusive naquelas que ainda não foram abordadas e tuteladas pela estrutura legislativa, em razão da cláusula geral que estende a proteção dos direitos para assegurar uma tutela absoluta ${ }^{14}$. Dessa forma são reconhecidas e validadas prerrogativas que fazem parte da individualidade do ser humano, devendo ser incluídas, considerada e defendidas como os direitos da personalidade positivados na ordem jurídica.

O direito geral da personalidade é reconhecido por meio do princípio da dignidade da pessoa humana, que compreende a cláusula geral de materialização e defesa do desenvolvimento do sujeito, em todos os seus aspectos, e a despeito de náo se configurar expressamente como tal nos dispositivos legais, opera como matriz de direitos, de modo que observa-se demais direitos desdobrados desse princípio central, não se exaurindo os direitos constitucionais da personalidade previstos no artigo $5^{\mathrm{o}^{15}}$. Assim, é possível, por meio da tutela geral, se inferir a identidade como um direito da personalidade, uma vez que essencial ao indivíduo.

\section{A identidade como elemento da personalidade}

Diante das modernas tecnologias, da inconstância das relaçóes, e dos riscos que essas novas situaçóes representam, é imperativo evidenciar que se encontra incluído na tutela da dignidade da pessoa humana o enfoque na identidade do homem em seu meio social, de forma precisa ${ }^{16}$. À vista disso, o conteúdo central que origina todos os demais direitos fundamentais

12 BORGES, Roxana Cardoso Brasileiro. Direitos da personalidade e autonomia privada. 2. ed. São Paulo: Saraiva, 2007, p. 24.

13 HUBMANN, 1967, p. 60, apud SZANIAWSKI, Elimar. Direitos da personalidade e sua tutela. 2. ed. São Paulo: Revista dos Tribunais, 2005, p. 114.

14 CANTALLI, Fernanda Borghetti. Direitos da personalidade: disponibilidade relativa, autonomia privada e dignidade humana. Porto Alegre: Livraria do advogado, 2009, p. 94.

15 SZANIAWSKI, Elimar. Direitos da personalidade e sua tutela. 2. ed. São Paulo: Revista dos Tribunais, 2005, p. 137-144.

16 SCHREIBER, Anderson. Direitos da personalidade. 2. ed. Sáo Paulo: Atlas, 2013, p. 213. 
do ser humano trata-se do princípio da dignidade humana, o qual relaciona o poder estatal e de particulares ${ }^{17}$.

O homem enquanto membro participativo da sociedade, anseia por se diferenciar dos demais indivíduos, a fim de que seja considerado um ser único, com características próprias, e individualizado, sendo a identidade o recurso que atende essa necessidade, consistindo na sua distinção perante o meio social, de modo que o ordenamento jurídico considera o nome, a imagem, a voz e os fatos da vida como componentes de identificação do sujeito ${ }^{18}$. No entanto, a identidade de um ser humano não se limita apenas aos elementos designados na legislação, existindo diversas características que singularizam um indivíduo.

É coerente sustentar que a identidade é um direito essencial de cada ser humano, considerando que se trata de um elemento que o caracteriza e o distingue, de sorte que o direito à identidade é protegido como um direito da personalidade, e por conseguinte, resulta na melhor coexistência de cada homem na sociedade ${ }^{19}$. Isso se deve ao fato de que, as diversas qualidades e especialidades naturais de cada indivíduo, conquanto que harmonizadas entre si, constituem uma comunidade estável e segura.

Os direitos da personalidade tem o escopo de amparar os bens jurídicos compreendidos pelo imaginário físico e psíquico do indivíduo, que inclui seus atributos mais relevantes, a através desses direitos são tutelados a essência da pessoa, e, portanto, figuram como objetos os, princípios e convicçôes que regem a existência do ser humano ${ }^{20}$. Assim, tem-se que a identidade é a exteriorização de todos os bens e ideias que o indivíduo decide compreender como aspecto que demonstra sua individualidade.

A identidade pessoal é um direito garantido a todo homem e é um dos fundamentos para o exercício dos demais direitos essenciais. Nessa perspectiva, Adriano de Cupis afirma que "A identidade constitui um bem por si mesma, independentemente do grau da posição social, da virtude ou dos defeitos do sujeito. A todo sujeito deve reconhecer-se o interesse a que sua individualidade seja preservada”. Essa individualidade impede que o homem seja considerado sem qualquer diferenciação e facilmente substituível ${ }^{21}$.

Apesar de não se encontrar positivado expressamente no Código Civil, é notório que o direito a identidade merece ser tutelado pelo ordenamento pátrio, de modo que diversas expressôes da personalidade são amparadas como como direito da personalidade pelo efeito da cláusula geral de proteçáo de dignidade da pessoa humana, sendo impositivo a investigaçáo da existência de matérias que são olvidadas pelo legislador, mas que são basilares para a formação da personalidade humana ${ }^{22}$.

17 SZANIAWSKI, Elimar. Direitos da personalidade e sua tutela. 2. ed. São Paulo: Revista dos Tribunais, 2005, p. 142.

18 CUPIS, Adriano de. Os direitos da personalidade. São Paulo: Quorum, 2008, p. 179-180.

19 OLIVEIRA, Maria Izabel Pinto de; BARRETO, Wanderlei de Paula. Direito à identidade como direito da personalidade. Revista Jurídica Cesumar - Mestrado, v. 10, n. 1, p. 199-215, jan./jun. 2010, p. 213. Disponível em: https://periodicos.unicesumar.edu.br/index.php/revjuridica/article/view/1439/1005. Acesso em: 01 mar. 2021.

20 BORGES, Roxana Cardoso Brasileiro. Direitos da personalidade e autonomia privada. 2. ed. São Paulo: Saraiva, 2007, p. 20.

21 CUPIS, Adriano de. Os direitos da personalidade. São Paulo: Quorum, 2008, p. 185.

22 SCHREIBER, Anderson. Direitos da personalidade. 2. ed. São Paulo: Atlas, 2013, p. 15. 
Os direitos de caráter moral são fundamentais a todo ser humano, posto que compóem a ligação entre o homem e seu meio social, sendo o a identidade o primeiro desses direitos, e nessa conformidade, configuram como elementos individualizadores do sujeito necessários para as relações nos diversos grupos em que se participa, tais como a família, o comércio, o negócio. promovendo a caracterização da pessoa e evitando o equívoco com as demais ${ }^{23}$. Nessa perspectiva, Oliveira e Barreto expóem que esse bem atua como elo entre o indivíduo, si mesmo e suas necessidades, de forma que a coexistência harmônica dos homens com os demais se submete à conservação e respeito mútuo a esse direito ${ }^{24}$.

A defesa da identidade é fundamental para as comunidades indígenas de forma ainda mais intensa, dado que são mais significativos para a formação da identidade desses povos tradicionais os valores equivalentes e os vínculos comunitários, bem como que esses grupos são governados por costumes coletivos que são incorporados na formação intersubjetiva da identidade dos indivíduos, sendo que primordial para a concreção de todos os demais direitos está a garantia do território natural ${ }^{25}$.

A continuidade dessas comunidades está condicionada à garantia das terras tribais, que atuam como entrave à convivência, intervenção e assimilação por outros povos, experiências danosas ao desenvolvimento indígena, visto que os indígenas que foram desapossados das terras e interagiram com não-indígenas seriam condenados ao aniquilamento, caso não fossem objeto de defesa, principalmente em razão de sua inexperiência para atividades da "sociedade civilizada", e pelo esgotamento ao lidar com pensamentos e comportamentos diferentes da cultura nativa ${ }^{26}$.

O direito à identidade pessoal é a garantia da manifestação genuína da personalidade do indivíduo, que é inigualável, protegendo a prerrogativa de a pessoa exteriorizar com transparência quem de fato é, em seus aspectos físicos, morais e intelectuais, não se limitando ao nome, mas a todas características próprias, justificando seu caráter basilar, posto que na sociedade atual os relacionamentos e atos da vida civil estão cada vez mais uniformizados, de forma que a identidade opera contrapondo-se a eventuais ofensas e favorecendo a descoberta e o desenvolvimento da autenticidade do homem ${ }^{27}$.

A doutrina majoritariamente compreende, portanto, que os direitos da personalidade não são circunscritos a um rol estabelecido na legislação constitucional ou civil, sendo possível considerar a identidade como integrante da personalidade, e logo, parte desses direitos. É manifesto também que a identidade não se restringe a apenas alguns aspectos mais conhecidos como o nome, podendo ser incluída como parte de caracterização do homem, principalmente ao se abordar a questáo de povos indígenas.

$\mathrm{O}$ instrumento da identidade, consoante a teoria de Zygmunt Bauman, é empregado principalmente no sentido de admitir que as diferenças existem na sociedade, e que são

23 BITTAR, Carlos Alberto. Os direitos da personalidade. 8. ed. São Paulo: Saraiva, 2015, p. 195.

24 OLIVEIRA, Maria Izabel Pinto de; BARRETO, Wanderlei de Paula. Direito à identidade como direito da personalidade. Revista Jurídica Cesumar - Mestrado, v. 10, n. 1, p. 199-215, jan./jun. 2010, p. 202. Disponível em: https://periodicos.unicesumar.edu.br/index.php/revjuridica/article/view/1439/1005. Acesso em: 01 mar. 2021.

25 SARMENTO, Daniel. Dignidade da pessoa humana: conteúdo, trajetórias e metodologia. Belo Horizonte: Fórum, 2016, p. 278-281.

26 RIBEIRO, Darcy. A política indigenista brasileira. Rio de Janeiro: Ministério da Agricultura, 1962, p. 143-144.

27 SCHREIBER, Anderson. Direitos da personalidade. 2. ed. São Paulo: Atlas, 2013, p. 216. 
inalteráveis e perpétuas, e assim, que os costumes, crenças, práticas e línguas, mesmo pertencentes mesmo a minoria dos indivíduos devem ser observados e conservados, sendo a identidade "um conceito altamente contestado", e uma esforço concomitante em oposição à anulação e o desmembramento ${ }^{28}$. Essa dinâmica se aplica completamente em relação à história dos indígenas que ao mesmo tempo em que se qualificam como sujeitos de direitos em igualdade com os demais, devem ter a liberdade de manter sua própria cultura.

A história revela que as comunidades indígenas, inicialmente detentoras das terras naturais, foram desapropriadas e exterminadas. De acordo com o antropólogo Darcy Ribeiro, a repreensão e censura das crenças tribais, assim como a rejeição aos padrões e convicçóes que nos quais se amparavam a consideração de uns em relação aos outros, foram fatores determinantes para o cenário desastroso das comunidades indígenas ${ }^{29}$.

O Decreto no 6.040 de 2007, estabelece a Política Nacional de Desenvolvimento Sustentável dos Povos e Comunidades Indígenas, e determina que esses povos e comunidades são grupos que possuem culturas distintas e que se identificam de tal forma, dispondo de peculiares formas de organização social, dependendo do território para a manifestação de sua cultura, religião, economia e vida social ${ }^{30}$. Posto isto, é possível estabelecer que a cultura, principalmente no que tange aos indígenas, é primordial para a realização plena e completa do princípio universal da dignidade da pessoa humana, posto que confere significado e distingue as diversas comunidades indígenas que se encontram no território brasileiro.

\section{$4 O$ reconhecimento cultural indígena enquanto materializaçáo da dignidade humana}

A dignidade humana figura-se como princípio fundamental, da qual emana os demais princípios e é incumbida por nortear as regras jurídicas, sendo o centro da personalidade humana, de modo que é forçoso a identificação e a legitimação da tutela geral da personalidade por meio do princípio da dignidade da pessoa humana, compreendida em uma cláusula geral de concretizaçáo, salvaguarda e da garantia do livre desenvolvimento da personalidade, e dos direitos decorrentes ${ }^{31}$.

A tônica da dignidade humana se manifestou com maior intensidade a partir da 2a Grande Guerra, do holocausto e dos reveses que se sucederam, sendo elaborada a Declaração Universal dos Direitos Humanos em 1948, que suscitou majorar esse princípio como superior às vontades políticas do Estado, uma vez que anuncia que a igualdade de todos os seres humanos de desfrutar de liberdade, dignidade e direitos, não obstante a situação econômica, social, política e cultural, garantindo a todo indivíduo humano, e logo, detentor da condição humana, exigir

28 BAUMAN, Zygmunt. Identidade: entrevista a Benedetto Vecchi. Tradução Carlos Alberto Medeiros. Rio de Janeiro: Jorge Zahar, 2005, p. 83-84.

29 RIBEIRO, Darcy. A politica indigenista brasileira. Rio de Janeiro: Ministério da Agricultura, 1962, p. 130.

30 BRASIL. Decreto no 6.040 de 07 de fevereiro de 2007. Institui a Política Nacional de Desenvolvimento Sustentável dos Povos e Comunidades Tradicionais. Diário Oficial da Uniáo, Brasília, DF, 08 de fevereiro, 2007. Disponível em: http://www.planalto.gov.br/ccivil_03/_ato2007-2010/2007/decreto/d6040. Acesso em: 04 mar. 2021.

31 CANTALLI, Fernanda Borghetti. Direitos da personalidade: disponibilidade relativa, autonomia privada e dignidade humana. Porto Alegre: Livraria do advogado, 2009, p. 87-88. 
esses direitos universais, ressaltando que a Constituição Federal de 1988 albergou como matriz do texto constitucional as ideias dessa Declaração ${ }^{32}$.

A essência desse princípio fundamental, se traduz no conteúdo lecionado por Ingo Wolfgang Sarlet, ao expor que é o atributo inerente e natural, que diferencia cada indivíduo humano, fazendo-o merecedor do respeito e estima pelos entes públicos e particulares, o que importa em um conjunto de direitos e deveres fundamentais, e que assegura e promove o mínimo existencial, bem como sua participação ativa e responsável nos propósitos e objetivos de sua vida e na vida em sociedade, mediante o respeito aos demais ${ }^{33}$.

O princípio da dignidade da pessoa humana é considerado o núcleo central dos demais direitos fundamentais como a igualdade, liberdade e justiça, porquanto tutela os bens e direitos indispensáveis para a existência do indivíduo em todos os seus aspectos, manifestando-se por esse preceito valores morais de toda a humanidade, e indispensável essa a garantia a todos, tão somente em razão de sua existência, permanecendo esse direito associado com valores de liberdade e autonomia ${ }^{34}$.

Com referência à liberdade, o professor Alessandro Severino Vallér Zenni enuncia que o homem, exclusivamente em virtude de sua racionalidade, compreende em seu íntimo a liberdade necessária para proceder conscientemente, a fim de alcançar seu pleno desenvolvimento, o que fomenta o agir ético, e nessa conformidade, utiliza a liberdade diante de seus propósitos, o que demonstra a importância dessa garantia para a concretização de seus valores e dessa forma, sua própria realizaçãa ${ }^{35}$.

A autonomia é profundamente atrelada à noção de liberdade pessoal e livre desenvolvimento da personalidade, uma vez que a liberdade se trata de elemento fundamental para a concreção dos direitos da personalidade ${ }^{36}$. O bem-estar e a ampliação da almejada condição de vida dos indivíduos são resultantes desse desenvolvimento pessoal, vez que amplia as possibilidades e decisôes concernentes à realização de seus desejos e suas necessidades ${ }^{37}$.

É a dignidade da pessoa humana que valida a oportunidade de cada indivíduo exercer suas próprias vontades e delimitar seu plano de vida ${ }^{38}$. Isto posto, os direitos da liberdade e da dignidade humana ensejam a caracterização da autonomia privada como um direito fundamental, sendo esta uma dinâmica correspondente a relaçôes de vários indivíduos, para a formação da própria identificação, de modo que a liberdade se limita pela própria dignidade da pessoa humana, em relação aos demais ${ }^{39}$.

32 BITTAR, Carlos Alberto. Os direitos da personalidade. 8. ed. São Paulo: Saraiva, 2015, p. 41-42.

33 SARLET, Ingo Wolfgang. Dignidade da pessoa humana e direitos fundamentais na Constituição Federal de 1988. 7. ed. Porto Alegre: Livraria do Advogado, 2009, p. 67.

34 BARROSO, Luís Roberto. Curso de Direito Constitucional Contemporâneo: Os conceitos fundamentais e a construçáo do novo modelo. 8. ed. Sáo Paulo: Saraiva, 2019, p. 245-246.

35 ZENNI, Alessandro Severino Vallér. A crise do direito liberal na pós-modernidade. Porto Alegre: Sergio Antonio Fabris, 2006, p. 106-107.

36 BORGES, Roxana Cardoso Brasileiro. Direitos da personalidade e autonomia privada. 2. ed. São Paulo: Saraiva, 2007, p. 246

37 ANJOS FILHO, Robério Nunes dos. Direito ao desenvolvimento. São Paulo: Saraiva, 2013, p. 44.

38 RIDOLA, Paolo. A dignidade humana e o "princípio liberdade" na cultura constitucional europeia. Coordenação e revisão técnica Ingo Wolfgang Sarlet; trad. Carlos Luis Strapazzon, Tula Wesendonck. Porto Alegre: Livraria do Advogado, 2014, p. 115.

39 CANTALLI, Fernanda Borghetti. Direitos da personalidade: disponibilidade relativa, autonomia privada e dignidade humana. Porto Alegre: Livraria do advogado, 2009, p. 206-209. 
No que concerne aos povos indígenas, a ideia de dignidade humana foi abordada por Francisco de Vitória, justamente no período colonial, ao defender a qualidade desses indivíduos como sujeitos de direitos, em razão do seu direito natural e condição humana, sendo necessário portanto, ser reconhecidos enquanto proprietários das terras nacionais ${ }^{40}$. Interessa destacar que mesmo no início do período de expansão territorial, e existindo um desconhecimento generalizado a respeito dos povos indígenas, já se defendia, ainda que minoritariamente, a tese de que tais indivíduos não poderiam ser objetificados, mas tratados com a dignidade decorrente da essência humana.

É elementar que se renegue a ideia, por vezes enraizada na convicção da população como um todo, da superioridade existente entre os povos, seja tecnológica, capital, científica ou cultural. De fato, por um longo período, e ainda na atualidade persiste o preconceito e a intolerância ao se abordar a questáo dos povos indígenas, de modo que essas percepçóes e condutas acabam por comprometer o pleno desenvolvimento desses indivíduos. No entanto, as práticas culturais, crenças e costumes não podem ser óbice para a concretização de uma vida digna, conforme o leciona Ingo Wolfgang Sarlet

[...] a dignidade - ao menos de acordo com o que parece ser a opiniáo largamente majoritária - independe das circunstâncias concretas, já que inerente a toda e qualquer pessoa humana, visto que, em princípio, todos - mesmo o maior dos criminosos - são iguais em dignidade, no sentido de serem reconhecidos como pessoas - ainda que năo se portem de forma igualmente digna nas suas relaçôes com os seus semelhantes, inclusive consigo mesmos ${ }^{41}$.

A proteção dos povos indígenas, no que tange ao Estado brasileiro, relaciona-se essencialmente à garantia do direito à diferença, correlatado ao direito à identidade pessoal, porquanto que é justamente a atenção de juristas sobre a conservação desses povos a condição que assegura a sobrevivência de tribos a despeito das violências e sobreposiçóes de culturas, considerando que esse direito é dispositivo que produz tolerância nas normas jurídicas quando na colisão das culturas indígenas e dominantes, preservando a identidade da história, cultura e sociedade de indivíduos ou grupos ${ }^{42}$.

O vocábulo cultura, no conceito amplo, é associado ao indivíduo, denotando a quantidade de informaçóes, ideias e crenças agregadas que solidificam condutas e regem atitudes na vida em sociedade e no mundo, promovidas por um processo de escolhas de noçóes, pensamento, informaçôes e vivências, constituintes da própria personalidade humana ${ }^{43}$. A cultura, assim sendo, trata-se de uma escolha e do direito de eleição, o que em tudo se relaciona com a liberdade, fundamental ao ser humano.

É possível sintetizar a cultura como a concepção implícita de mundo, por meio da qual os indivíduos determinam a maneira apropriada de como agem em determinadas circunstâncias, e ainda o conjunto de princípios, atos, crenças e hábitos que estabelecem e fundamentam o mdo

40 MIRANDOLA, 1986, p. 52,53 apud SARLET, Ingo Wolfgang. Dignidade da pessoa humana e direitos fundamentais na Constituição Federal de 1988. 7. ed. Porto Alegre: Livraria do Advogado, 2009, p. 34.

41 SARLET, Ingo Wolfgang. Dignidade da pessoa humana e direitos fundamentais na Constituição Federal de 1988. 7. ed. Porto Alegre: Livraria do Advogado, 2009, p. 49.

42 SCHREIBER, Anderson. Direitos da personalidade. 2. ed. São Paulo: Atlas, 2013, p. 255.

43 REALE, Miguel. Paradigmas da cultura contemporânea. 2. ed. São Paulo: Saraiva, 2005, p. 2. 
de vida e a organização de certos grupos ${ }^{44}$. À vista disso, privar indivíduos de sua cultura original, ou ainda subjugá-la a outra considerada mais apropriada, significa arruinar todo o seu projeto de vida.

A garantia da existência e crescimento de uma cultura é atrelada a tutela da dignidade de pessoas determinadas, que ante a ausência ou degradação de seu ambiente cultural teriam sua identidade lesionada, ressaltando-se a relevância e a necessidade da defesa do território, essencial para os povos tradicionais, devendo o Estado exercer esta tutela mediante todos os recursos que possua $^{45}$. Tem-se, portanto, atrelado ao princípio fundamental da dignidade humana o direito dos indivíduos de possuírem culturas distintas, devendo ser salvaguardados todos os componentes básicos dessas culturas.

O direito à diferença é abordado pela doutrina como semelhante, em alguns aspectos, ao direito à igualdade substancial, porquanto que se respalda na máxima de se tratar desigualmente os desiguais, não com o escopo de suprimir as desigualdades de suas características sociais, mas de tolerar, reconhecer e respeitar as diversas formas organização e costumes ${ }^{46}$. Nesse sentido, defende-se de que o direito à igualdade é perpetuado no direito à aceitação da diferença, e é exercido a partir do momento que a diferença produz inferiorizaçáo, bem como que o direito à diferença decorre da hipótese em que a igualdade distorce a identidade do indivíduo ${ }^{47}$.

É cada vez mais relevante o diálogo entre culturas que além de analisar as situações jurídicas próprias de multiplicidade cultural, promove o conhecimento a toda sociedade, possibilitando a relação com padróes e bagagens distintas, e, em relação à sociedade brasileira, é extensa a contribuição das comunidades indígenas tradicionais para o estudo dos direitos, que compreende com primazia o princípio da solidariedade, que por vezes é escassa na cultura individualista, bem como que percebe profundamente os valores atinentes ao direito ambiental em razão de sua constante convivência com a natureza ${ }^{48}$.

A concepção de cultura é complexa e compreende vários elementos que são indispensáveis para a formação humana, sendo também indissociável da ideia de liberdade e autonomia, considerando que o indivíduo racionalmente elege os fatos que se sucedem no decorrer de sua vida por meio de uma análise de interpretaçóes e recursos que produzem sua ação, não por imposição de terceiros, mas pela própria consciência ${ }^{49}$. Assim sendo, percebe-se a correlação entre cultura e os direitos fundamentais.

A essência e conteúdo da dignidade da pessoa humana não pode ser traduzido a partir de uma ideia de execução precisa e singular, porquanto que a compreensão do que é elementar é alterada conforme a perspectiva, cultura e desenvolvimento de cada povo e das situaçóes vivenciadas por cada homem ${ }^{50}$. Desse modo, não é coerente realizar um juízo de valor para

44 EAGLETON, Terry. A ideia de cultura. Trad. Sandra Castello Branco. São Paulo: UNESP, 2005, p. 50-51.

45 SARMENTO, Daniel. Dignidade da pessoa humana: conteúdo, trajetórias e metodologia. Belo Horizonte: Fórum, 2016, p. 280-283.

46 SCHREIBER, Anderson. Direitos da personalidade. 2. ed. São Paulo: Atlas, 2013, p. 254.

47 SANTOS, Boaventura de Souza. Direitos humanos: o desafio da interculturalidade. Revista Direitos Humanos, vol. 2, p. 18, 2009. Disponível em: http://www.dhnet.org.br/dados/revistas/a_pdf/revista_sedh_dh_02.pdf. Acesso em: 03 mar. 2021.

48 SARMENTO, Daniel. Dignidade da pessoa humana: conteúdo, trajetórias e metodologia. Belo Horizonte: Fórum, 2016, p. 292-294.

49 REALE, Miguel. Paradigmas da cultura contemporânea. 2. ed. São Paulo: Saraiva, 2005, p. 21.

50 SCHREIBER, Anderson. Direitos da personalidade. 2. ed. São Paulo: Atlas, 2013, p. 8. 
determinadas crenças e práticas culturais, tampouco desconsiderar e dissipar sua existência e importância.

Por intermédio de todas as considerações elencadas no trabalho, é possível concluir que os direitos são de alguma forma conectados, vinculados e dependentes entre si, sendo sua completa realizaçáo e efetivaçáo sujeita à execuçáo de todos. Uma vez que alguma prerrogativa humana é violada, e neste caso, debate-se a identidade ou o reconhecimento cultural, todos os demais direitos são sucessivamente lesionados, considerando que são integrantes do princípio da dignidade humana.

\section{Consideraçóes finais}

O princípio da dignidade da pessoa humana trata-se do alicerce que compreende todos os demais direitos protegidos contra o poder público e particulares. É manifesto que esse princípio não pode ser banalizado a fim de tutelar toda e qualquer manifestação da vontade humana, sem algum critério. Trata-se, assim, de um direito matriz, a partir do qual se desdobram prerrogativas fundamentais à formação homem enquanto ser participativo na comunidade em que pertence, e que protege elementos essenciais ao desenvolvimento humano com integridade.

No ordenamento jurídico está determinado a defesa de atributos intrínsecos e fundamentais para a formação do ser humano, isto é, características que o definem e lhe dão conteúdo, que são os chamados diretos da personalidade. Não obstante, é impossível a legislação incluir todos os aspectos do indivíduo, principalmente em razão de a inconstância das relaçóes e situações que demandam atenção jurídica, de modo que as prerrogativas principais foram expostas em um rol de direitos na Constituição Federal e no Código Civil.

$\mathrm{O}$ artigo procurou relacionar a possibilidade de estender os direitos da personalidade a prerrogativas não evidenciadas a direitos basilares à formação do homem, com fundamente na cláusula geral da tutela da personalidade, ou seja, a dignidade humana, especificamente no que tange ao direito à identidade pessoal, que retrata e qualifica o sujeito perante os demais indivíduos, distinguindo-o e o tornando singular, não apenas pelo nome e imagem, mas por atributos que são eletivos como a crença, os hábitos e a cultura.

Os indígenas, desde os primeiros contatos com os demais povos colonizadores precisaram se esforçar para garantir a própria vida e integridade física. Em razão de exercícios religiosos e práticas assimilacionistas, muitos povos foram incorporados ou deixaram de existir. As comunidades indígenas que subsistiram ainda enfrentam muitas dificuldades para serem respeitadas e efetivamente protegidas. A cultura indígena é um dos elementos mais aviltados e menosprezados desde o princípio, sendo considerada inferior e censurável.

A sociedade em geral, na maioria das vezes, possui dificuldade e resistência em compreender e aceitar a diferença, seja em crenças, práticas, costumes ou culturas. O interessante é que o Brasil é um país caracterizado pela diversidade de povos e pelo seu multiculturalismo. Essa realidade decorre principalmente da mistura de povos colonizadores, imigrantes e nativos, bem como da gigante espaço demográfico que permite a construção de novas culturas conforme as ideias são alteradas. 
$\mathrm{O}$ ato de constatar e considerar as culturas diversas com respeito exterioriza a observância ao princípio da dignidade da pessoa humana que confere autonomia e independência a todos os indivíduos a alcançar sua própria realização. O princípio da igualdade envolve também considerar a diferença como parte natural da vida em comunidade, necessária e importante que confere relevância e interesse à nação brasileira.

Por fim, importante manifestar que além de a cultura ser vinculada à dignidade da pessoa humana, como forma de realização do desenvolvimento pleno e exteriorização de todas as particularidades que compóem o indivíduo, em relação aos povos indígenas que já foram extremamente ofendidos e lesionados, implica em não suprimir as crueldades cometidas no passado, mas determinar um futuro de vida com integridade e liberdade.

\section{Referências}

AMARAL, Francisco. Direito civil: introdução. 5.ed. Rio de Janeiro: Renovar, 2003.

ANJOS FILHO, Robério Nunes dos. Direito ao desenvolvimento. Sáo Paulo: Saraiva, 2013.

BARROSO, Luís Roberto. Curso de Direito Constitucional Contemporâneo: Os conceitos fundamentais e a construção do novo modelo. 8. ed. São Paulo: Saraiva, 2019.

BAUMAN, Zygmunt. Identidade: entrevista a Benedetto Vecchi. Tradução Carlos Alberto Medeiros. Rio de Janeiro: Jorge Zahar, 2005.

BITTAR, Carlos Alberto. Os direitos da personalidade. 8. ed. São Paulo: Saraiva, 2015.

BORGES, Roxana Cardoso Brasileiro. Direitos da personalidade e autonomia privada. 2. ed. São Paulo: Saraiva, 2007.

BRASIL. [Constituição (1988)]. Constituição da República Federativa do Brasil. Brasília, DF: Senado Federal, 1988. Disponível em: http://www.planalto.gov.br/ccivil_03/constituicao/ constituicao.htm. Acesso em: 05 mar. 2021.

BRASIL. Decreto no 6.040 de 07 de fevereiro de 2007. Institui a Política Nacional de Desenvolvimento Sustentável dos Povos e Comunidades Tradicionais. Diário Oficial da União, Brasília, DF, 08 de fevereiro, 2007. Disponível em: http://www.planalto.gov.br/ccivil_03/_ ato2007-2010/2007/decreto/d6040. Acesso em: 04 mar. 2021.

CANTALLI, Fernanda Borghetti. Direitos da personalidade: disponibilidade relativa, autonomia privada e dignidade humana. Porto Alegre: Livraria do advogado, 2009.

CUPIS, Adriano de. Os direitos da personalidade. Sáo Paulo: Quorum, 2008.

EAGLETON, Terry. A ideia de cultura. Trad. Sandra Castello Branco. São Paulo: UNESP, 2005.

OLIVEIRA, Maria Izabel Pinto de; BARRETO, Wanderlei de Paula. Direito à identidade como direito da personalidade. Revista Jurídica Cesumar - Mestrado, v. 10, n. 1, p. 199-215, 
jan./jun. 2010. Disponível em: https://periodicos.unicesumar.edu.br/index.php/revjuridica/ article/view/1439/1005. Acesso em: 01 mar. 2021.

RIDOLA, Paolo. A dignidade humana e o "princípio liberdade" na cultura constitucional europeia. Coordenação e revisão técnica Ingo Wolfgang Sarlet; trad. Carlos Luis Strapazzon, Tula Wesendonck. Porto Alegre: Livraria do Advogado, 2014.

SANTOS, Boaventura de Souza. Direitos humanos: o desafio da interculturalidade. Revista Direitos Humanos, vol. 2, p. 10-18, 2009. Disponível em: http://www.dhnet.org.br/dados/ revistas/a_pdf/revista_sedh_dh_02.pdf. Acesso em: 03 mar. 2021.

SARLET, Ingo Wolfgang. Dignidade da pessoa humana e direitos fundamentais na Constituição Federal de 1988. 7. ed. Porto Alegre: Livraria do Advogado, 2009.

SARMENTO, Daniel. Dignidade da pessoa humana: conteúdo, trajetórias e metodologia. Belo Horizonte: Fórum, 2016.

SCHREIBER, Anderson. Direitos da personalidade. 2. ed. São Paulo: Atlas, 2013.

SZANIAWSKI, Elimar. Direitos da personalidade e sua tutela. 2. ed. São Paulo: Revista dos Tribunais. 2005.

REALE, Miguel. Paradigmas da cultura contemporânea. 2. ed. São Paulo: Saraiva, 2005.

RIBEIRO, Darcy. A politica indigenista brasileira. Rio de Janeiro: Ministério da Agricultura, 1962.

ZANINI, Leonardo Estevam. Direitos da Personalidade: aspectos essenciais. São Paulo: Saraiva, 2011.

ZENNI, Alessandro Severino Vallér. A crise do direito liberal na pós-modernidade. Porto Alegre: Sergio Antonio Fabris, 2006. 